\title{
Hypoxic tolerance of marine benthic fauna
}

\author{
Rutger Rosenberg, Birthe Hellman, Birgitta Johansson
}

University of Göteborg Marine Research Station, Kristineberg, S-450 34 Fiskebäckskil, Sweden

\begin{abstract}
In stratified coastal marine waters hypoxia is a growing problem affecting bottom-dwelling animals. Earlier studies suggest oxygen concentrations of about $2 \mathrm{ml} \mathrm{l}^{-1}$ (Rosenberg 1980) as the lower tolerance limit for many benthic species in coastal areas. We exposed several conspicuous infaunal species on the NE Atlantic continental shelf, contained within their sediment habitat, to gradually reduced oxygen concentrations. Tolerance to hypoxia for the 8 species examined was in the range of 0.5 to $1.0 \mathrm{ml} \mathrm{l}^{-1}$ ( 8 to $15 \%$ saturation), which they could tolerate for several days to weeks. The ophiuroid Amphiura filiformis left its protected position in the sediment at an oxygen concentration of $0.85 \mathrm{ml} \mathrm{l}^{-1}$ (13\% sat.), whereas A. chiajei emerged from the sediment at $0.54 \mathrm{ml} \mathrm{l}^{-1}$ ( $8 \%$ sat.).
\end{abstract}

\section{INTRODUCTION}

The increasing input of nutrients to urbanised marine coastal areas over the last decades, in stratified water bodies, has given rise to larger areas with intermittent hypoxia. Earlier studies on the effects of hypoxia on coastal benthic sublittoral fauna suggested great faunal reductions at oxygen concentrations $<2 \mathrm{ml} \mathrm{l}^{-1}$ (Rosenberg 1980), whereas deep-sea benthos can maintain rather high densities even in oxygen concentrations around $1 \mathrm{ml}^{-1}$ (Rhoads \& Morse 1971, Rosenberg et al. 1983). Recent studies in the Kattegat, between Denmark and Sweden, suggest that parts of these benthic communities can also withstand oxygen concentrations of around $1 \mathrm{ml} \mathrm{l}^{-1}$ for several weeks, but localised high mortality can occur (Rosenberg \& Loo 1988, Baden et al. 1990a), probably where the oxygen concentrations are temporarily lower.

Here we present results from laboratory experiments with benthic animals exposed to hypoxia within their natural sediment. All species are conspicuous species of the north-east Atlantic continental shelf benthos. To our knowledge no such experiments have previously been performed, although tolerance and physiological response to hypoxia of benthic animals without sediment have been examined (Theede et al. 1969, 1973).

\section{MATERIAL AND METHODS}

All experiments were performed in darkness in a salinity of $32 \%$ and temperatures of 10 to $11^{\circ} \mathrm{C}$. Ani- mals were not fed. Oxygen concentration was measured continuously or daily with an YSI oxygen meter, calibrated daily by Winkler titration. The sediments were silt-clay with an organic carbon content of $3.2 \%$ and a total nitrogen content of $0.4 \%$ of dry weight. Sediments were obtained from the same sites as animals at 25 to $35 \mathrm{~m}$ depth off the Swedish west coast $\left(58^{\circ} 20^{\prime} \mathrm{N}, 11^{\circ} 22^{\prime} \mathrm{E}\right)$, except for experiments with Mya arenaria and Cerastoderma edule, where sandy sediment was obtained from $1 \mathrm{~m}$ depth nearby. Animals were acclimatised in sediments for $>10 \mathrm{~d}$ before the oxygen concentration was reduced by bubbling nitrogen gas into the natural sea water overlying the sediments. Circulation in the system was maintained by recirculating water at 3 to $41 \mathrm{~min}^{-1}$ through the tanks. About $10 \%$ of the water was changed weekly and the ammonium concentration was kept low (generally $<10 \mu \mathrm{g} \mathrm{l}^{-1}$ ). The oxygen concentration was reduced gradually from saturation to 10 to $15 \%$ saturation over about $10 \mathrm{~d}$ and then maintained between that level and $6 \%$ saturation (Fig. 1). No significant mortality was observed during the gradual reduction in oxygen saturations $>15 \%$ ( $p>0.05$ log-rank test; Kalbfleich \& Prentice 1980).

All experiments were set up as 2 controls (> $90 \%$ sat.) and 2 parallels where oxygen was reduced. Since there were no significant differences ( $t$-test) in mortality between pairs of controls or hypoxia treatments during the course of the experiments, these pairs were combined in the analyses.

Two series of experiments were performed. In 1988-89 we used four 3001 tanks and placed animals in boxes 


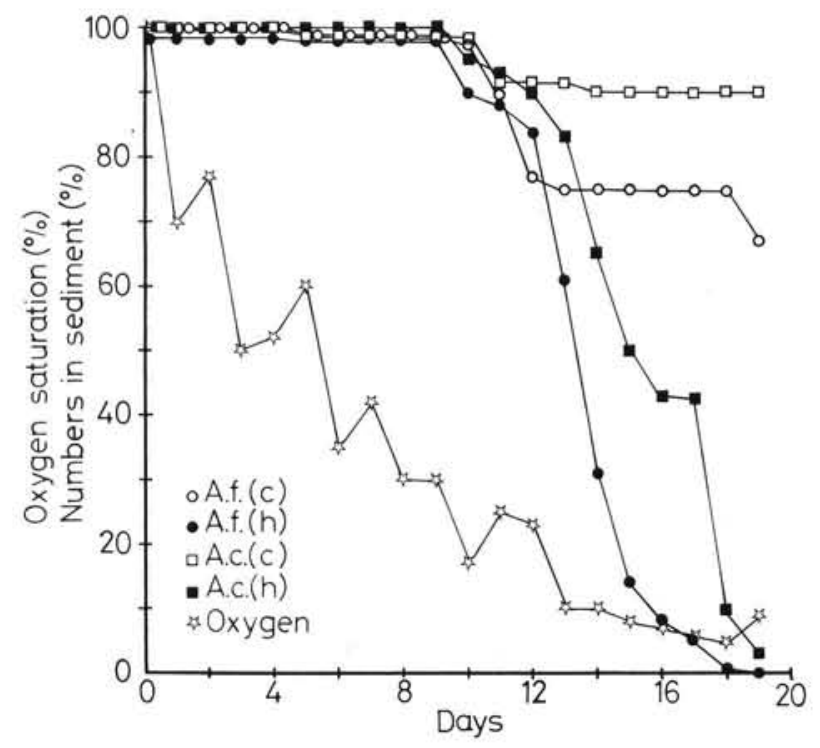

Fig. 1. Mean oxygen saturation (\%) in the hypoxic aquaria during deoxygenation and percentage of Amphiura filiformis (A. f.) and A. chiajei (A. c.) on the sediment surface during $19 \mathrm{~d}$ (Expt 4). (c): control; (h): hypoxia. Oxygen concentration in control was $>90 \%$ (not shown)

$(28 \times 18 \mathrm{~cm}$ and $5 \mathrm{~cm}$ high) with their sediment. Each box contained 12 to 40 individuals of 1 species. Two such similar experiments (Expts $1 \& 2$ ) were run with 7 or 8 infaunal species (identified below) in each, and 1 with the lobster Homarus gammarus (Expt 3). Seven lobsters ( $50 \%$ females) were included in each tank with sand and PVC tubes for protection against predation.

In 1990-91 we used 'thin aquaria' $(19 \times 1 \mathrm{~cm}$ and 9 $\mathrm{cm}$ high) filled with sediment to the top (Fig. 2). These were placed in 4 larger aquaria $(160 \times 10$ and $25 \mathrm{~cm}$ high) with sea water ( $80 \mathrm{l}$ in each system): 2 were controls saturated with oxygen, and 2 in which the oxygen concentration was gradually lowered. Eight 'thin aquaria' were placed in each larger aquarium, allowing us to observe the vertical position in the sediment of some of the 6 animals in each 'thin aquarium'. Current speed over the sediment surface was ca $15 \mathrm{~cm}$ $\mathrm{min}^{-1}$. Total number of animals of each species in the control and in the hypoxia treatment was 96. Natural sediment for these experiments was collected using a box-corer. By removing the front glass of each thin aquarium' it could be pushed into the sediment from the side to enclose segments of 'undisturbed' sediment. Animals obtained from the same site were later added to these aquaria and the animals buried themselves within minutes. Two such similar experiments were performed, one with echinoderms Amphiura filiformis and $A$. chiajei (Expt 4 ) and the other with bivalves Abra alba and A. nitida (Expt 5). The 'thin aquaria' with these species ( 1 species in each aquarium) were mixed at random in the larger aquaria to avoid any potential bias due to small differences in oxygen concentrations. Amphiura filiformis and Abra alba can act as suspension feeders, whereas Amphiura chiajei and Abra nitida are deposit feeders.

\section{RESULTS}

The exposure time in oxygen concentrations $<1 \mathrm{ml}$ $1^{-1}$ was $43 \mathrm{~d}$ in Expt 1 and $32 \mathrm{~d}$ in Expt 2 . Mortality data and behaviour are presented in Table 1. During this period, the bivalves Abra alba, A. nitida, Cerastoderma edule and Mya arenaria and the echinoderms Amphiura filiformis and A. chiajei all showed significantly higher mortalities in hypoxia treatments in both Expts 1 \& 2, which had the same mean oxygen concentrations $\left(6.3 \mathrm{ml} \mathrm{l}^{-1}, \mathrm{SE}=0.03 ; 10.0 \%\right.$ sat. $)$, compared to the control $(\mathrm{p}<0.0001$; log-rank test; Kalbfleich \& Prentice 1980). Similarly, significantly higher mor-

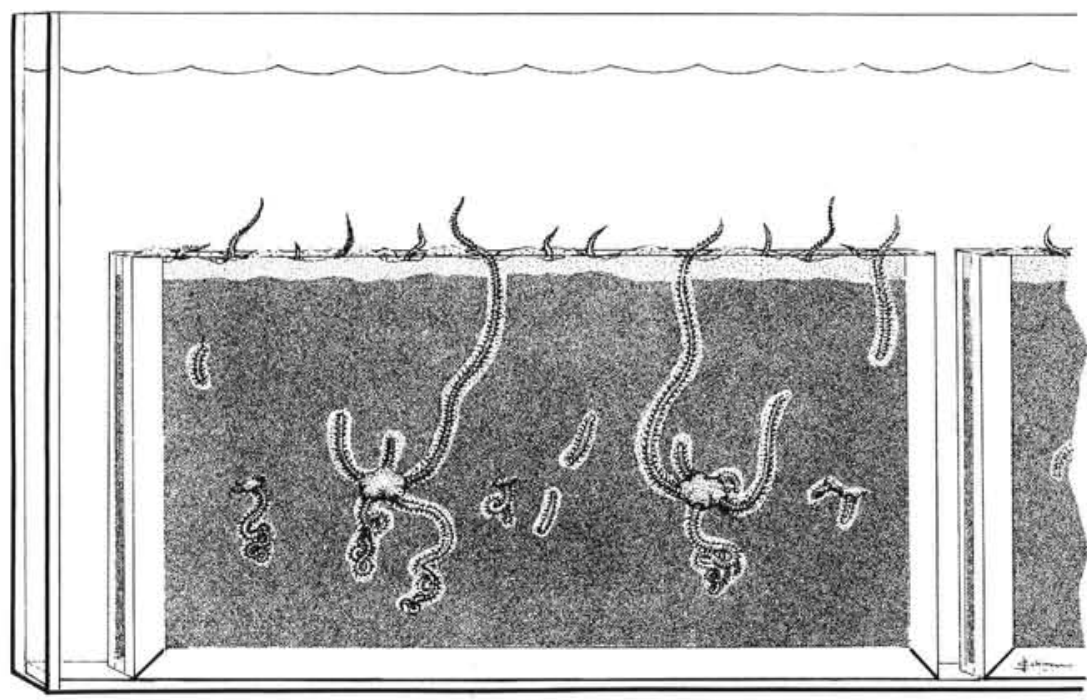

Fig. 2. Pictoral representation of thin aquarium' with sediment and Amphiura filiformis (2 specimens can clearly be seen) with body-discs at sediment depth of ca $5 \mathrm{~cm}$. Light sediment: oxic material; dark sediment: anoxic. The 'thin aquarium' is in a larger aquarium with sea water 
Table 1. Numerical mortality of benthic fauna in Controls (C, $>90 \%$ oxygen saturation) and in Expts 1 \& 2 (E, ca $10 \%$ oxygen saturation). Number ( $\mathrm{n}$ ) of individuals in both controls and experiments are given. Estimated numbers of infauna recorded on the sediment surface or number of siphons of Mya arenaria stretching out above the sediment surface are given in brackets

\begin{tabular}{|c|c|c|c|c|c|c|}
\hline \multirow[t]{2}{*}{ Species } & \multicolumn{3}{|c|}{ Experiment 1} & \multicolumn{3}{|c|}{ Experiment 2} \\
\hline & $\mathrm{n}$ & C & E & $\mathrm{n}$ & C & E \\
\hline Abra alba & 30 & $1(5)$ & $19(19)$ & 60 & $2(0)$ & $54(28)$ \\
\hline A. nitida & 25 & $6(1)$ & $24(9)$ & 60 & $6(5)$ & $54(52)$ \\
\hline Amphiura filiformis & 40 & $12(18)$ & $40(40)$ & 80 & $18(4)$ & $72(45)$ \\
\hline A. chiajei & 40 & $6(15)$ & $30(34)$ & 80 & $7(8)$ & $72(37)$ \\
\hline Arctica islandica & 24 & $3(0)$ & $4(2)$ & 24 & $3(0)$ & $10(0)$ \\
\hline Cerastoderma edule & 30 & $16(22)$ & $30(30)$ & 60 & $6(12)$ & $59(60)$ \\
\hline Mya arenaria & 24 & $4(5)$ & $11(9)$ & 24 & 1 & 22 \\
\hline Ophiura albida & & & & 20 & 0 & 17 \\
\hline
\end{tabular}

talities were also noted for bivalve Arctica islandica $(\mathrm{p}<0.05)$ and echinoderm Ophiura albida $(\mathrm{p}<0.0001)$ in Expt 2. In Expt 1 no difference was recorded in survival of $A$. islandica. The tolerance limit for $50 \%$ mortality $\left(\mathrm{TL}_{50}\right)$ of each population could not be recorded in detail as some species died in the sediments and were not observed until a few days later.

When oxygen saturations dropped to ca $10 \%$ in Expts $1 \& 2$ many individuals left their position in the sediments and appeared on the sediment surface. The Wilcoxon Signed Rank Test was used to test the null hypothesis that no difference could be observed between the number of animals on the sediment surface and the numbers in the sediment. This could be rejected ( $\mathrm{p}<0.01)$ for Amphiura filiformis, A. chiajei and Abra alba in both experiments, and also for Mya arenaria in Expt 1 and for $A$. nitida and Cerastoderma edule in Expt 2. The amphiurans were observed at times to stand on their arm-tips with the body-disc elevated a few $\mathrm{cm}$ above the sediment surface or to lie inverted on the surface. $M$. arenaria frequently stretched their thick siphons out of the sediment like chimneys, sometimes as far as $10 \mathrm{~cm}$ up into the water column. Arctica islandica maintained their position close to the sediment surface and in hypoxia expanded their openings and apparently their siphon diameter.

Expt 3 with Homarus gammarus was run for $45 \mathrm{~d}$ with a gradual decrease in oxygen concentration after $10 \mathrm{~d}$. After ca $30 \mathrm{~d}$ the animals in hypoxia $\left(1.6 \mathrm{ml} \mathrm{l}^{-1}\right.$, $25 \%$ sat.) were sluggish. The first lobster died after 40 $\mathrm{d}$ in $0.63 \mathrm{ml} \mathrm{l}^{-1}$ (10\% sat.). Over the next $24 \mathrm{~h}$ all but one lobster died, whereas all survived in the controls.

Expt 4 with 'thin aquaria' allowed a closer examination of the position of Amphiura filiformis and A. chiajei in the sediment (Fig. 1). The distance from the surface down to the discs in the sediment was 4.8 to $5.9 \mathrm{~cm}$ (Fig. 2) with no significant difference (ANOVA-test, p $>0.4$ ) between species or experiments. At specific low oxygen concentrations, a majority of the individuals left the sediment. Half the number of A. filiformis were found on the surface at $0.85 \mathrm{ml} \mathrm{l}^{-1}(13 \%$ sat.) and half of $A$. chiajei at $0.54 \mathrm{ml} \mathrm{l}^{-1}$ ( $8 \%$ sat.). Significantly more amphiurans in oxygen concentrations of 0.34 to $0.62 \mathrm{ml}$ $1^{-1}$ (6 to $10 \%$ sat.) were found each day on the sediment surface compared to the control ( $\mathrm{p}<0.05$, Chi-square test). At these oxygen concentrations significantly more specimens of $A$. filiformis were found on the sediment surface each day compared to A. chiajei $(\mathrm{p}<0.05$, Chisquare test; Fig. 1).

Measurements of redox potential (electrode diameter $2 \mathrm{~mm}$ ) in these experiments gave positive recordings in the top $2 \mathrm{~cm}$. Correlations between redox potential and sediment depth were calculated. The slopes of the lines were described by linear regression and negative significances were obtained in all 4 treatments $(\mathrm{p}<0.002)$. No differences between the slopes of the lines could, however, be observed either between the controls and the hypoxic aquaria, or between the beginning and the end of the experiment.

The significantly ( $\mathrm{p}<0.001$, log-rank test; Kalbfleich \& Prentice 1980) higher mortality of Abra alba and A. nitida under hypoxia compared to the control (Expt 5 with 'thin aquaria') is shown in Fig. 3. After $11 \mathrm{~d}$ (Days 14 to 24 ) in hypoxial conditions (mean $0.86 \mathrm{ml}^{-1}, 8.0 \%$ sat.) ca $40 \%$ of the individuals of both species were still alive. Siphons of $A$. alba were recorded stretching out of the sediment into anoxic water 3.5 times more often than in the control $(\mathrm{p}<0.0001, t$-test), and also significantly more often than for A. nitida ( $p<0.001)$. The redox potential in general was positive in the top $0.5 \mathrm{~cm}$ with a maximum down to $1 \mathrm{~cm}$, with no trend during the experiment.

\section{DISCUSSION}

These experiments show that in northern European waters some conspiciuous benthic infaunal species and Homarus gammarus can tolerate oxygen concentrations in the range of 0.5 to $1.0 \mathrm{ml} \mathrm{l}^{-1}$ ( 8 to $15 \%$ sat.) for 


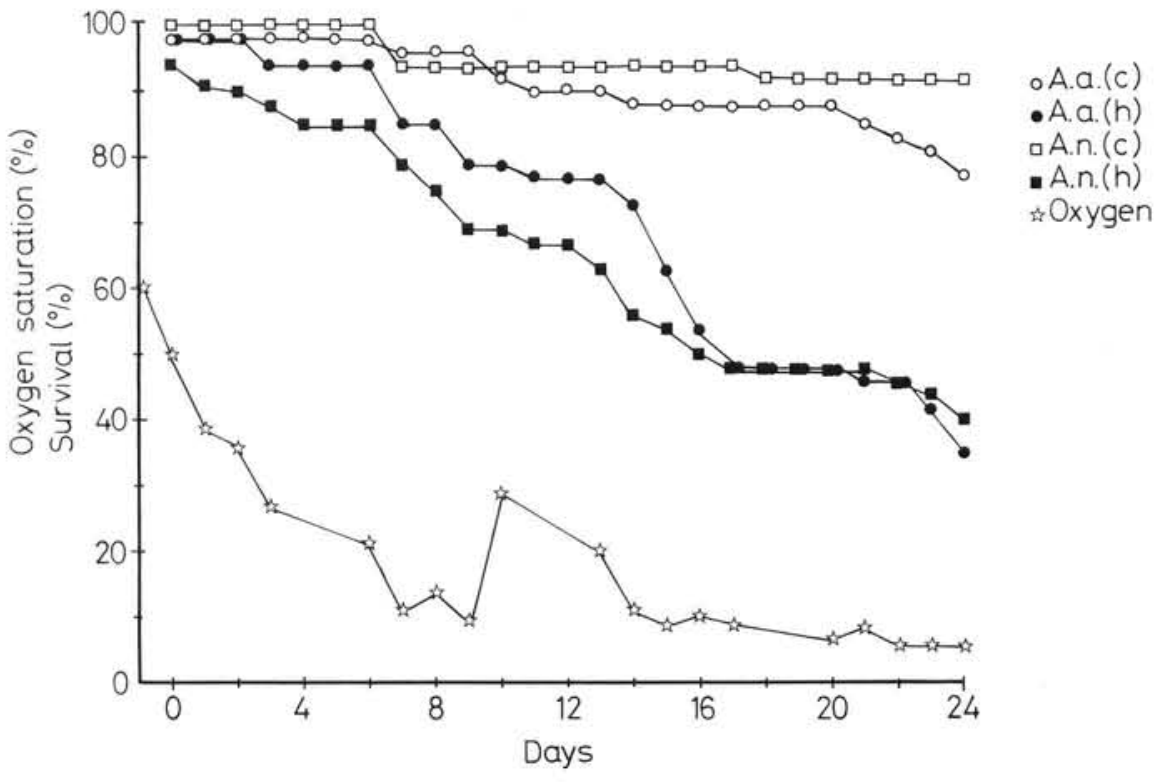

Fig. 3. Mean oxygen saturation (\%) in the hypoxic aquaria during deoxygenation and percentage mortality of Abra alba (A. a.) and A. nitida (A. n.) (Expt 5). (c): control; (h): hypoxia. Oxygen concentration in control was $>90 \%$ (not shown) several days to weeks. This is in agreement with results from field observations in the Kattegat, where infauna was reduced after several weeks of exposure to approximately the same oxygen concentrations (Rosenberg \& Loo 1988, Baden et al. 1990a). H. gammarus showed a tolerance to hypoxia similar to the burrowing Norway lobster Nephrops norvegicus which can stand $10 \%$ saturation for 2 to $4 \mathrm{~d}$ (Baden et al. 1990b). For $H$. americanus it has been shown that oxygen acclimation had no effect on the lethal oxygen level, whereas acclimation in different temperatures and salinities influenced the tolerance to hypoxia (McLeese 1956).

In these experiments most species showed behavioural responses in oxygen concentrations slightly higher than those found to induce mortalities; they left their protected position in the sediment and were exposed on the sediment surface. These threshold responses appeared to be induced at a certain oxygen concentration and did not occur gradually. Effects on e.g. embryonic survival and gamete viability may occur at higher oxygen concentrations than the behavioural responses observed here. The higher tolerance to hypoxia shown by Amphiura chiajei compared to $A$. filiformis, both in the field (Rosenberg \& Loo 1988) and in these experiments, is likely to be due to the 5 times higher respiration rate shown by the latter species (Buchanan 1964). Facultative anaerobiosis is, however, also widespread among benthic animals and the use of such pathways in the metabolism varies between species (Pamatmat 1980). Oxygen consumption by benthic animals declines notably at low oxygen concentrations (Theede et al. 1973), and the level at which animals switch to a lower metabolic rate is also likely to vary between species.
To observe benthic faunal behaviour in the field, a remote-controlled submersible vehicle with a videocamera and an attached YSI oxygen meter was used in the Kattegat in September 1987 (Baden et al. 1990a). Oxygen concentration at this time was ca $0.8 \mathrm{ml} \mathrm{l}^{-1}$ (12\% sat.) and the arms of Amphiura filiformis could be clearly seen actively moving high up in the water, whereas Ophiura albida was standing on its arm-tips with the body-disc elevated above the bottom surface, probably to reach a micro-layer with slightly higher oxygen.

One possible explanation for the higher tolerance of benthic animals to hypoxia (found both in our experiments and in the Kattegat), compared to earlier findings, could be that the oxygen concentration in some of the earlier studies was not measured close to the bottom, but at some distance above the sediment. It is known that the gradient of oxygen concentration can be very steep in the water immediately overlying the sediment (Jörgensen 1980, Rosenberg \& Loo 1988). Thus, it is possible that the benthic animals in those earlier studies experienced lower oxygen levels than those reported.

In the experiments presented here, oxygen concentration was reduced in the sea water, and not by increasing the biological oxygen demand in the sediment (e.g. organic enrichment). The reason was that in the Kattegat, annual respiration was found to be higher in the sub-halocline water than in the sediment (Rydberg et al. 1990), and when sampling the sediments in that hypoxic area in the autumn we have only rarely smelled the presence of $\mathrm{H}_{2} \mathrm{~S}$. The tolerance to hypoxia of benthic infauna may not be identical if low oxygen concentration is initiated within the sediment. 
Over the last decades, hypoxia has spread in some stratified marine waters, most probably as a result of recently increased inputs of nitrogen and phosphorus causing high phytoplankton production. The importance of benthic animals to sedimentary bio-geochemical processes and as prominent agents in the transportation and transformation of nutrients is well established (Kristensen et al. 1985). Benthic organisms significantly amplify the nitrification and denitrification processes, including the removal of nitrogen as a gas from the sea to the atmosphere. This removal can account for up to $50 \%$ of the nitrogen input in coastal areas (Seitzinger et al. 1984). When the oxygen concentration drops below about $10 \%$ saturation, defaunation is initiated and the potential for nitrogen removal is likely to be significantly reduced. Instead $\mathrm{NH}_{4}{ }^{+}$can be released in higher amounts to the water and the eutrophication process may be self-accelerating, as indicated for the upper Chesapeake Bay on the east coast of the USA (Kemp et al. 1990).

Acknowledgements. We thank the Swedish Environmental Protection Agency for financial support, Robert Diaz, Thomas Pearson and 3 anonymous reviewers for comments on the manuscript, and Marita Olsson for statistical help.

\section{LITERATURE CITED}

Baden, S. P., Loo, L. O., Pihl, L., Rosenberg, R. (1990a). Effects of eutrophication on benthic communities including fish: Swedish West Coast. Ambio 19: 113-122

Baden, S. P., Pihl, L., Rosenberg, R. (1990b). Effects of oxygen depletion on the ecology, blood physiology and fishery of the Norway lobster Nephrops norvegicus. Mar. Ecol. Prog. Ser. 67: 141-155

Buchanan, J. B. (1964). A comparative study of some features of the biology of Amphiura filiformis and Amphiura chiajei (Ophiuroidea) considered in relation to their distribution. J. mar. biol. Ass. U.K. 44: 565-576

Jörgensen, B. B. (1980). Seasonal oxygen depletion in the

This article was submitted to the editor bottom waters of a Danish fjord and its effect on the benthic community. Oikos 34: 68-76

Kalbfleich, J. D., Prentice, R. L. (1980). The statistical analysis of failure time data. J. Wiley \& Sons, New York

Kemp, W. M., Sampou, P., Caffrey, J., Mayer, M., Henriksen, K., Boynton, W. R. (1990). Ammonium recycling versus denitrification in Chesapeake Bay sediments. Limnol. Oceanogr. 35: 1545-1563

Kristensen, E., Jensen, M. H., Andersen, T. K. (1985). The impact of polychaete (Nereis virens Sars) burrows on nitrification and nitrate reduction in estuarine sediments. J. exp. mar. Biol. Ecol. 85: 75-91

McLeese, D. (1956). Effects of temperature, salinity and oxygen on the survival of the American Lobster. J. Fish. Res. Bd Can. 13: 247-272

Pamatmat, M. M. (1980). Facultative anaerobiosis of benthos. In: Tenore, R. T., Coull, B. C. (eds.) Marine benthic dynamics. Univ. South Carolina Press, Columbia, p. 69-90

Rhoads, D. C., Morse, J. W. (1971). Evolutionary and ecologic significance of oxygen-deficient marine basins. Lethaia 4: 413-428

Rosenberg, R. (1980). Effect of oxygen deficiency on benthic macrofauna. In: Freeland, J. H., Farmer, D. M., Levings, C. D. (eds.) Fjord oceanography. Plenum Publ. Corp., New York, p. 499-514

Rosenberg, R., Arntz, W. W., Chuman de Flores, W., Flores, L. A., Carbajal, G., Finger, I., Tarazona, J. (1983). Benthos biomass and oxygen deficiency in the upwelling system off Peru. J. mar. Res. 41: 263-279

Rosenberg, R., Loo, L. O. (1988). Marine eutrophication induced oxygen deficiency: effects on soft bottom fauna, Western Sweden. Ophelia 29: 213-225

Rydberg, L., Edler, L., Floderus, S., Granéli, W. (1990). Interaction between supply of nutrients, primary production, sedimentation and oxygen consumption in SE Kattegat. Ambio 19: 134-141

Seitzinger, S. P., Nixon, S. W., Pilson, M. E. Q. (1984). Denitrification and nitrous oxide production in a coastal marine ecosystem. Limnol. Oceanogr. 29: 73-83

Theede, H., Ponat, A., Hiroki, K., Schlieper, C. (1969). Studies on the resistance of marine bottom invertebrates of oxygen-deficiency and hydrogen sulphide. Mar. Biol. 2: 325-339

Theede, H., Scaudinn, J., Saffé, F. (1973). Ecophysiological studies on four Nereis species of the Kiel Bay. Oikos, Suppl. 15: 246-252

Manuscript first received: July 30, 1991

Revised version accepted: November 18, 1991 